\title{
Lung cancer lymph node micrometastasis detection using real-time polymerase chain reaction: Correlation with vascular endothelial growth factor expression
}

Chukwumere E. Nwogu, MD, ${ }^{\mathrm{a}, \mathrm{b}}$ Sai Yendamuri, MD, ${ }^{\mathrm{a}, \mathrm{b}}$ Wei Tan, MS, ${ }^{\mathrm{c}}$ Eric Kannisto, MS, ${ }^{\mathrm{a}}$ Paul Bogner, MD,${ }^{\mathrm{d}}$ Carl Morrison, MD, DVM, ${ }^{\mathrm{d}}$ Richard Cheney, MD,${ }^{\mathrm{d}}$ Elisabeth Dexter, MD, ${ }^{\mathrm{a}, \mathrm{b}}$ Anthony Picone, MD, PhD, ${ }^{a}$ Mark Hennon, MD, ${ }^{\mathrm{a}, \mathrm{b}}$ Alan Hutson, $\mathrm{PhD},{ }^{\mathrm{c}}$ Mary Reid, $\mathrm{PhD},{ }^{\mathrm{e}}$ Alex Adjei, MD, PhD, ${ }^{\mathrm{e}}$ and Todd L. Demmy, $\mathrm{MD}^{\mathrm{a}, \mathrm{b}}$

Objectives: Lymph node staging provides critical information in patients with non-small cell lung cancer (NSCLC). Lymphangiogenesis may be an important contributor to the pathophysiology of lymphatic metastases. We hypothesized that the presence of lymph node micrometastases positively correlates with vascular endothelial growth factors (VEGFs) A, C, and D as well as VEGF-receptor-3 (lymphangiogenic factors) expression in lymph nodes.

Methods: Forty patients with NSCLC underwent preoperative positron emission tomography-computed tomography and mediastinoscopy. Real-time polymerase chain reaction (RT-PCR) assays for messenger RNA expression of epithelial markers (ie, cytokeratin 7; carcinoembryonic antigen-related cell adhesion molecule 5; and palate, lung, and nasal epithelium carcinoma-associated protein) were performed in selected fluorodeoxyglucose-avid lymph nodes. VEGF-A, VEGF-C, VEGF-D, and VEGF receptor-3 expression levels were measured in primary tumors and lymph nodes. Wilcoxon rank sum test was run for the association between the RT-PCR epithelial marker levels and VEGF expression levels in the lymph nodes.

Results: RT-PCR for cytokeratin 7; carcinoembryonic antigen-related cell adhesion molecule 5; or palate, lung, and nasal epithelium carcinoma-associated protein indicated lymph node micrometastatic disease in 19 of 35 patients (54\%). There was a high correlation between detection of micrometastases and VEGF-A, VEGF-C, VEGF-D, or VEGF receptor-3 expression levels in lymph nodes. Median follow-up was 12.6 months.

Conclusions: RT-PCR analysis of fluorodeoxyglucose-avid lymph nodes results in up-staging a patient's cancer. Micrometastases correlate with the expression of VEGF in lymph nodes in patients with NSCLC. This may reflect the role of lymphangiogenesis in promoting metastases. (J Thorac Cardiovasc Surg 2013;145:702-8)

Lung cancer is the most frequent cause of cancer death in both men and women in the United States and will account for about $27 \%$ of all estimated cancer deaths in $2012 .{ }^{1}$ The staging of lung cancer plays a critical role in efforts to combat this disease. Lymph node metastasis is the most important prognostic factor in locoregional lung cancer. However, the accurate identification of all lymph node disease in patients remains an elusive goal. This is reflected

From the Departments of Thoracic Surgery, ${ }^{\mathrm{a}}$ Biostatistics, ${ }^{\mathrm{c}}$ Pathology, ${ }^{\mathrm{d}}$ and Medicine, ${ }^{\mathrm{e}}$ Roswell Park Cancer Institute, Buffalo, NY; and the Department of Surgery, University at Buffalo, The State University of New York, Buffalo, NY.

Supported by The National Cancer Institute grant No. 1 K23 CA122182 and a Thoracic Surgery Foundation for Research and Education Mentored Clinical Scientist Development Award.

Disclosures: Authors have nothing to disclose with regard to commercial support.

Read at the 92nd Annual Meeting of The American Association for Thoracic Surgery, San Francisco, California, April 28-May 2, 2012.

Received for publication May 1, 2012; revisions received Aug 17, 2012; accepted for publication Dec 10, 2012.

Address for reprints: Chukwumere E. Nwogu, MD, Thoracic Surgery Department, Roswell Park Cancer Institute, Elm \& Carlton St, Buffalo NY 14263 (E-mail: chumy.nwogu@ roswellpark.org).

$0022-5223 / \$ 36.00$

Copyright $(\odot) 2013$ by The American Association for Thoracic Surgery

http://dx.doi.org/10.1016/j.jtcvs.2012.12.023 in the modest 5-year survival (73\%) reported in the earliest stage of non-small cell lung cancer (NSCLC) (denoted as stage IA by the International Association for the Study of Lung Cancer). ${ }^{2}$ Nearly $40 \%$ of patients who are nodenegative will develop recurrent disease and die within 2 years. ${ }^{3}$ This is believed to be due to understaging of patients' lung cancer; that is, under-recognition of micrometastases by standard hematoxylin and eosin (H\&E) staining of lymph nodes. Thus, better staging methods are necessary to stratify patients, make therapeutic choices, and evaluate the effectiveness of various treatment modalities in clinical trials. Intensive pathologic techniques such as serial sectioning, immunohistochemistry (IHC), and real-time polymerase chain reaction (RT-PCR) are more sensitive in detecting these micrometastases. ${ }^{4-7}$ However, these techniques are labor intensive and expensive. Thus, they can practically be applied only to a limited number of lymph nodes in each patient. Multiple techniques for sentinel lymph node mapping have been studied as a means of selecting a few lymph nodes per patient for detailed pathologic analysis. ${ }^{8-11}$ Following a small 10-patient pilot study ${ }^{12}$ to investigate the feasibility of a handheld gamma probe to detect 


\section{Abbreviations and Acronyms \\ CK-7 = cytokeratin 7 \\ CEACAM5 $=$ carcinoembryonic antigen-related cell adhesion molecule 5 \\ FDG = fluorodeoxyglucose \\ $\mathrm{H} \& \mathrm{E} \quad=$ hematoxylin and eosin \\ IHC = immunohistochemistry \\ mRNA $=$ messenger RNA \\ NSCLC $=$ non-small cell lung cancer \\ PLUNC = palate, lung, and nasal epithelium carcinoma-associated protein \\ RT-PCR = real-time polymerase chain reaction VEGF = vascular endothelial growh factor}

lymph node fluorodeoxyglucose (FDG) avidity in patients undergoing NSCLC surgery, we embarked on a larger study to assess its clinical utility.

Malignant cells metastasize from the primary tumor to other organs via either the lymphatic or vascular network. Indeed, tumor metastasis to regional lymph nodes often represents the first step of tumor dissemination and serves as a major prognostic indicator for the progression of human cancers. ${ }^{13}$ Improved therapy for lung cancer requires better fundamental understanding of the molecular mechanisms leading to lymphatic metastasis. Lymphangiogenesis has been suggested as an essential component in lymph node metastasis. ${ }^{14-16}$ The vascular endothelial growth factor (VEGF)-C/VEGF-D/VEGFR-3 axis is the best validated signaling system for promoting lymphangiogenesis associated with solid tumors and the metastatic spread of tumor cells to lymph nodes. ${ }^{14}$ VEGF-A has also been shown to influence lymphangiogenesis. ${ }^{17}$

This report focuses on the correlation of the presence of micrometastases with VEGF-A, VEGF-C, VEGF-D, and VEGF receptor-3 expression in the lymph nodes of a small cohort of patients who received lymph node mapping during their surgical resection.

\section{METHODS}

Our Institutional Review Board approved a radioguided lymph node mapping study on September 6, 2007, for 100 patients with resectable, clinical stage I or II NSCLC. Individual patient consent was obtained. Ancillary studies using molecular markers were written into the protocol. An exploratory subset of 40 patients was selected for correlation of lymph node epithelial marker expression with VEGF-A, VEGF-C, VEGF-D, and VEGF receptor-3 expression in the same lymph nodes using reverse transcriptase-RT-PCR techniques.

A handheld gamma probe was used to select the lymph nodes for these assays as reported previously. ${ }^{12}$ On the day of surgery, each patient had intravenous injection of $10 \mathrm{mCi}$ F18-FDG followed by mediastinoscopy and anatomic lung resection if all the sampled mediastinal lymph nodes were benign on frozen section analysis. Standard thoracoscopic or open lung resection, as appropriate for the individual patient's tumor, was followed by complete thoracic lymphadenectomy. The lymph nodes were labeled using the American Thoracic Society/Naruke lymph node map. ${ }^{18}$ All harvested lymph nodes were scanned with the gamma probe outside the thoracic cavity to measure the gamma radiation resulting from any accumulated FDG in individual nodes. Intrathoracic radioactivity measurements were abandoned early in the study because of their unreliability due to interfering signals from the heart and great vessels. The resected tumor was similarly scanned outside the thorax. We compared the radioactive signals from the lymph nodes to each other. The FDG avid (hot) nodes had more than twice the signal intensity of the coldest lymph node in the entire thoracic field for that particular patient. An equal number of FDG avid (hot) and non-FDG avid (cold) nodes were selected for detailed pathologic analysis.

All surgically removed lymph nodes were bisected and examined by routine $\mathrm{H} \& \mathrm{E}$. The selected lymph nodes that were malignant on $\mathrm{H} \& \mathrm{E}$ staining required no further pathologic analysis. However, the selected lymph nodes that were not malignant on $\mathrm{H} \& \mathrm{E}$ staining were subjected to ultra-staging with multiple step sections: IHC using cytokeratin AE1/ AE3 and RT-PCR for cytokeratin 7 (CK-7); carcinoembryonic antigenrelated cell adhesion molecule 5 (CEACAM5); or palate, lung, and nasal epithelium carcinoma associated protein (PLUNC) (epithelial markers). These nodes were processed according to a standard protocol. After formalin fixation and embedding in paraffin, step sections of each lymph node were taken at 30 to 40 micron intervals. The sections were stained with $\mathrm{H} \& \mathrm{E}$ and an average of 10 serial sections were evaluated. IHC was performed with standard monoclonal mouse antihuman cytokeratin antibody clones AE1/AE3 (Dako Inc, Carpinteria, Calif). Formalin fixed, paraffinembedded tissue was pretreated with proteinase $\mathrm{K}$ for 5 minutes. The primary antibody was diluted 1:100 and then incubated on the slides for 30 minutes. All staining steps were performed on a Dako autostainer Plus machine (Model S3800; Dako Inc). Detection was done using the Mouse Envision+ system (Dako Inc). The testing was performed in a Clincal Laboratory Improvement Ammendment-certified clinical laboratory using prostate tissue as positive controls.

RNA extraction was performed on fresh primary tumors and an equal number of FDG-avid and nonavid lymph nodes. Tissues were homogenized with Trizol reagent (Invitrogen, Carlsbad, Calif). RNA was then precipitated from the aqueous phase using isopropanol. For quality control, 260:280 ratios were examined to confirm preparation purity and an RNA aliquot was run on an Agilent 2100 bioanalyzer (Agilent Technologies, Santa Clara, Calif) to confirm RNA integrity by generating an RNA integrity number value. Human messenger RNAs (mRNAs) for beta actin, CK7, VEGF-A, VEGF-C, VEGF-D, VEGF receptor-3, CEACAM5, and PLUNC were quantified by RT-PCR-based TaqMan Gene Expression Assays (Applied Biosystems, Foster City, Calif). The assay IDs were respectively, Hs99999903_m1, Hs00559840_m1, Hs00900055_m1, Hs1099203_m1, Hs01128659_m1, Hs01047677_m1, Hs00944025_m1, and Hs00213177_m1. Briefly, random primers and reagents provided with the High Capacity cDNA Reverse Transcription Kit (Applied Biosystems) were used to reverse transcribe $2 \mu \mathrm{g}$ total RNA from primary lung tumors and lymph nodes. The complementary DNA was used as template in 44-cycle PCR reactions on a 7900HT real-time PCR machine (Applied Biosystems). For each reaction, the quantification cycle $(\mathrm{Cq})$ value, approximately inversely proportional to $\log 2$ value of the concentration of the analyte RNA, was obtained with SDS software (version 2.3; Applied Biosystems). The average of $\mathrm{Cq}$ values of triplicate PCR reactions was used for analysis. $\mathrm{Cq}$ values for the mRNAs of interest were normalized by subtracting the value for beta actin mRNA from them. Beta actin is a highly conserved gene frequently used as a loading control in PCR assays.

Descriptive statistics such as frequencies and relative frequencies were computed for categorical variables. Numeric variables were summarized using simple descriptive statistics such as the mean, standard deviation, median, and range. The Wilcoxon rank sum test was used to correlate the lymph node micrometastatic status to normalized VEGF numeric 
TABLE 1. Patient demographic, surgical, and pathologic characteristics

\begin{tabular}{lcr}
\hline Demographic or characteristic & No. of patients $(\mathbf{N}=\mathbf{4 0})$ & $\%$ \\
\hline Age (y) & & \\
$\quad$ Median & 71 & \\
$\quad$ Range & $52-84$ & \\
Sex & & 17.5 \\
$\quad$ Man & 7 & 82.5 \\
$\quad$ Woman & 33 & \\
Clinical follow-up (mo) & & \\
Median & 12.6 & \\
Range & $3.7-31.6$ & \\
Clinical stage & & \\
I & 36 & 10 \\
II & 4 & 17.5 \\
Sex & & 82.5 \\
$\quad$ Man & 7 & \\
$\quad$ Woman & 33 & 2.5 \\
Operation performed & & \\
Lobectomy & 39 & 2.5 \\
Pneumonectomy & 1 & 2.5 \\
Tumor histology & & \\
$\quad$ Adenocarcinoma & 29 & \\
Squamous cell carcinoma & 9 & \\
Adenosquamous carcinoma & 1 & \\
Large cell carcinoma & 1 & \\
\hline
\end{tabular}

variables. Box plots were also provided to show the differences in VEGF expression according to lymph node micrometastatic status. A 0.05 nominal significance level was used in all testing. The expression of epithelial markers in lymph nodes was used to upstage individual patients' cancer. All statistical analyses were done using SAS (version 9.3; SAS Institute Inc, Cary, NC).

\section{RESULTS}

The demographic characteristics of the 40 patients in this study are shown in Table 1. The nodal stage distribution of patients by routine $\mathrm{H} \& \mathrm{E}, \mathrm{IHC}$, and quantitative RT-PCR are shown in Table 2. Immunohistochemistry and RT-PCR resulted in upstaging of patients' cancer, culminating in positive stage N1 and N2 lymph nodes in $45 \%$ and $15 \%$ of patients, respectively, by RT-PCR.

In the pathologic examination of the excised nodes, 5 patients had proven metastatic disease in the studied lymph nodes on $\mathrm{H} \& \mathrm{E}$, whereas IHC identified lymph node disease in 2 of the 35 patients without H\&E evidence for metastatic

TABLE 2. Lymph node staging distribution by various modalities

\begin{tabular}{lccc}
\hline & \multicolumn{3}{c}{ No. of patients in stage } \\
\cline { 2 - 4 } \multicolumn{1}{c}{ Staging modality } & N0 & N1 & N2 \\
\hline Routine H \& E & 35 & 4 & 1 \\
Immunohistochemistry & 33 & 6 & 1 \\
Quantitative RT-PCR & 16 & 18 & 6 \\
\hline
\end{tabular}

$H \& E$, Hematoxylin \& eosin; $R T$-PCR, reverse transcriptase-polymerase chain reaction. disease. The RT-PCR analysis suggested additional metastatic disease in 19 of 35 patients $(54 \%)$.

One hundred eighty-nine lymph nodes were evaluated by RT-PCR from the 40 patients. There was a highly positive correlation between RT-PCR detection of micrometastases and VEGF-A, VEGF-C, VEGF-D, or VEGF receptor-3 expression levels in lymph nodes (Table 3 ). Box plots are also provided to show the differences in location and scale of VEGF expression between malignant and nonmalignant lymph node groups (Figure 1).

There has been 1 death from disease and 2 other recurrences among patients who had micrometastatic disease detected in their lymph nodes by RT-PCR. In the group of patients without such disease detected in their lymph nodes, there has been only 1 recurrence so far. The difference in the overall and recurrence free survival between these 2 groups has not reached statistical significance during our limited follow-up period. This will be reassessed when the median follow-up reaches 24 months.

\section{DISCUSSION}

Increased understanding of the complex biology of lung cancer has led to advances in management of the disease. Accurate staging of individual patients remains a critical need. It guides the choice of therapy and stratifies patients appropriately for clinical trial of novel interventions. It also facilitates the comparison of treatment outcomes. Standard methods of evaluating thoracic lymph nodes (H\&E staining) can miss micrometastases. ${ }^{6,7,13,19-21}$ Intensive pathologic techniques such as serial sectioning, IHC, and RT-PCR are more sensitive in detecting these micrometastases. $^{4-7}$ However, these techniques are labor intensive and expensive. Thus, they can practically be applied only to a limited number of lymph nodes in each patient. We used a handheld gamma probe to select lymph nodes for measurement of the expression of mRNA for epithelial markers by RT-PCR.

Due to the greater sensitivity of RT-PCR for micrometastatic lymph node disease detection, we upstaged 19 of 35 patients $(54 \%)$ using this technique compared with routine pathology (H\&E). This is consistent with other RT-PCRbased studies. ${ }^{19,22,23}$ The data were reported on a per patient basis and not a per node basis. This is because decisions on adjuvant therapy would be based on the presence or absence of any lymph node metastases regardless of the number of lymph nodes involved. We are currently assessing survival based on the presence or absence of any micrometastatic disease in the lymph nodes (ie, 2 groups).

Concerns have been expressed that RT-PCR may be overly sensitive and may include false positives from mesothelial or endothelial cells within lymph nodes. The prognostic significance of RT-PCR detection of tumor-specific molecular markers has been shown by others. ${ }^{4,23,24} \mathrm{We}$ 
TABLE 3. Association between lymph node micrometastatic status and normalized vascular endothelial growth factor (VEGF) real-time polymerase chain reaction (RT-PCR) quantification cycles (Cqs) in lymph nodes

\begin{tabular}{|c|c|c|c|c|c|}
\hline \multirow[b]{2}{*}{ Normalized variable } & \multirow[b]{2}{*}{ Statistic } & \multicolumn{2}{|c|}{ Lymph node micrometastatic status } & \multirow[b]{2}{*}{ Overall } & \multirow[b]{2}{*}{$P$ value } \\
\hline & & Negative & Positive & & \\
\hline \multirow[t]{4}{*}{ VEGF-A } & Mean \pm SD & $3.4 \pm 1.7$ & $-0.7 \pm 4.1$ & $2.5 \pm 2.9$ & $<.0001$ \\
\hline & $\mathrm{n}$ & 148 & 41 & 189 & \\
\hline & Median & 3.5 & 0.8 & 2.9 & \\
\hline & Range & -2.7 to 6.5 & -14.1 to 3.7 & -14.1 to 6.5 & \\
\hline \multirow[t]{4}{*}{ VEGF-C } & Mean \pm SD & $5.1 \pm 1.7$ & $2.3 \pm 3.6$ & $4.5 \pm 2.5$ & $<.0001$ \\
\hline & $\mathrm{n}$ & 148 & 41 & 189 & \\
\hline & Median & 5.3 & 3.7 & 5 & \\
\hline & Range & -0.5 to 8.3 & -6.9 to 6.5 & -6.9 to 8.3 & \\
\hline \multirow[t]{4}{*}{ VEGF-D } & Mean \pm SD & $10.6 \pm 1.8$ & $6.7 \pm 4.1$ & $9.7 \pm 3$ & $<.0001$ \\
\hline & $\mathrm{n}$ & 148 & 41 & 189 & \\
\hline & Median & 10.9 & 7.6 & 10.5 & \\
\hline & Range & 5.9 to 14.3 & -1.5 to 13.2 & -1.5 to 14.3 & \\
\hline \multirow[t]{4}{*}{ VEGF receptor-3 } & Mean \pm SD & $6.7 \pm 1.5$ & $5.2 \pm 2.8$ & $6.4 \pm 2$ & $<.0025$ \\
\hline & $\mathrm{n}$ & 148 & 41 & 189 & \\
\hline & Median & 6.8 & 6.1 & 6.6 & \\
\hline & Range & 2.1 to 9.8 & -1.1 to 10.3 & -1.1 to 10.3 & \\
\hline
\end{tabular}

Lower Cq values reflect higher messenger RNA expression levels. $S D$, Standard deviation.

selected CK-7, CEACAM5, and PLUNC as the epithelial markers of interest based on literature review. ${ }^{4,22,23}$ The positive threshold for the expression levels of these markers in the lymph nodes was based on the minimal expression of the same markers in primary tumors. RTPCR is an imperfect gold standard for the presence of lymph node micrometastasis. Because there is no readily available method to verify its accuracy, we have to depend on the recurrence free survival of the 2 groups defined by the presence or absence of RT-PCR-detected nodal disease. Our median follow-up is still relatively short (12.6 months). Thus, it seems early to assess the survival effect of molecularly detected lymph node micrometastasis in our patient cohort. If the prognostic value of molecularly detected micrometastases is proven, it would be appropriate to run clinical trials to assess the benefit of adjuvant therapy in such patients. Chemotherapy is the logical choice, but the value of innovative intraoperative interventions, radiotherapy, and targeted agents in such patients could be investigated.

Malignant cells metastasize from the primary tumor to other organs via either the lymphatic or vascular network. Indeed, tumor metastasis to regional lymph nodes often represents the first step of tumor dissemination and serves as a major prognostic indicator for the progression of human cancers. ${ }^{13}$ It is currently believed that lymphatics provide the major route of lung cancer metastases. However, the exact molecular mechanisms remain unclear. There is experimental evidence that tumors can induce the formation of new lymphatic vessels (lymphangiogenesis) even before they metastasize to lymph nodes, and that metastastic tumor cells continue to induce lymphatic vessel growth within sentinel lymph nodes, possibly promoting their further metastatic dissemination. ${ }^{14}$ The VEGF-C, VEGF-D, and VEGF receptor-3 axis is the best-validated signaling system for promoting lymphangiogenesis associated with solid tumors and the metastatic spread of tumor cells to lymph nodes. ${ }^{14}$ The secreted glycoproteins VEGF-C or VEGF-D activate VEGF receptor-3, a cell surface receptor tyrosine kinase on lymphatic endothelium, leading to growth of lymphatic vessels. ${ }^{25}$ Overexpression of VEGF-C and/or VEGF-D by tumor cells increases peritumoral and/or intratumoral lymphangiogenesis, promotes metastasis to local lymph nodes, and may facilitate distant organ metastasis. The role of VEGF-A in angiogenesis via activation of its receptors, VEGF receptor-1 and VEGF receptor-2, has been extensively documented, but it has also been shown to influence lymphangiogenesis. ${ }^{17}$ As a means of exploring the role of lymphangiogenesis in the occurrence of nodal micrometastases, we measured VEGF-A, VEGF-C, VEGF-D, and VEGF receptor-3 expression in $1 \mathrm{mph}$ nodes. The $\mathrm{Cq}$ values for the mRNAs of interest were normalized by subtracting the value for beta actin mRNA from them (Table 3). Beta actin is a highly conserved gene frequently used as a loading control in PCR assays. Actins are proteins that are involved in cell motility, structure, and integrity. Thus, all the lymph nodes were expected to express beta actin. Note that lower $\mathrm{Cq}$ values reflect higher mRNA expression levels. The correlation analysis was performed with the VEGF Cq values as continuous variables and lymph node status as categorical values, either positive (malignant) or negative (nonmalignant). Our study showed a highly positive correlation between the expression of VEGFs A, C, D, and VEGF receptor-3 in lymph nodes and the presence of micrometastases in those same nodes. This is consistent with the lymphangiogenesis literature. It would be worthwhile 


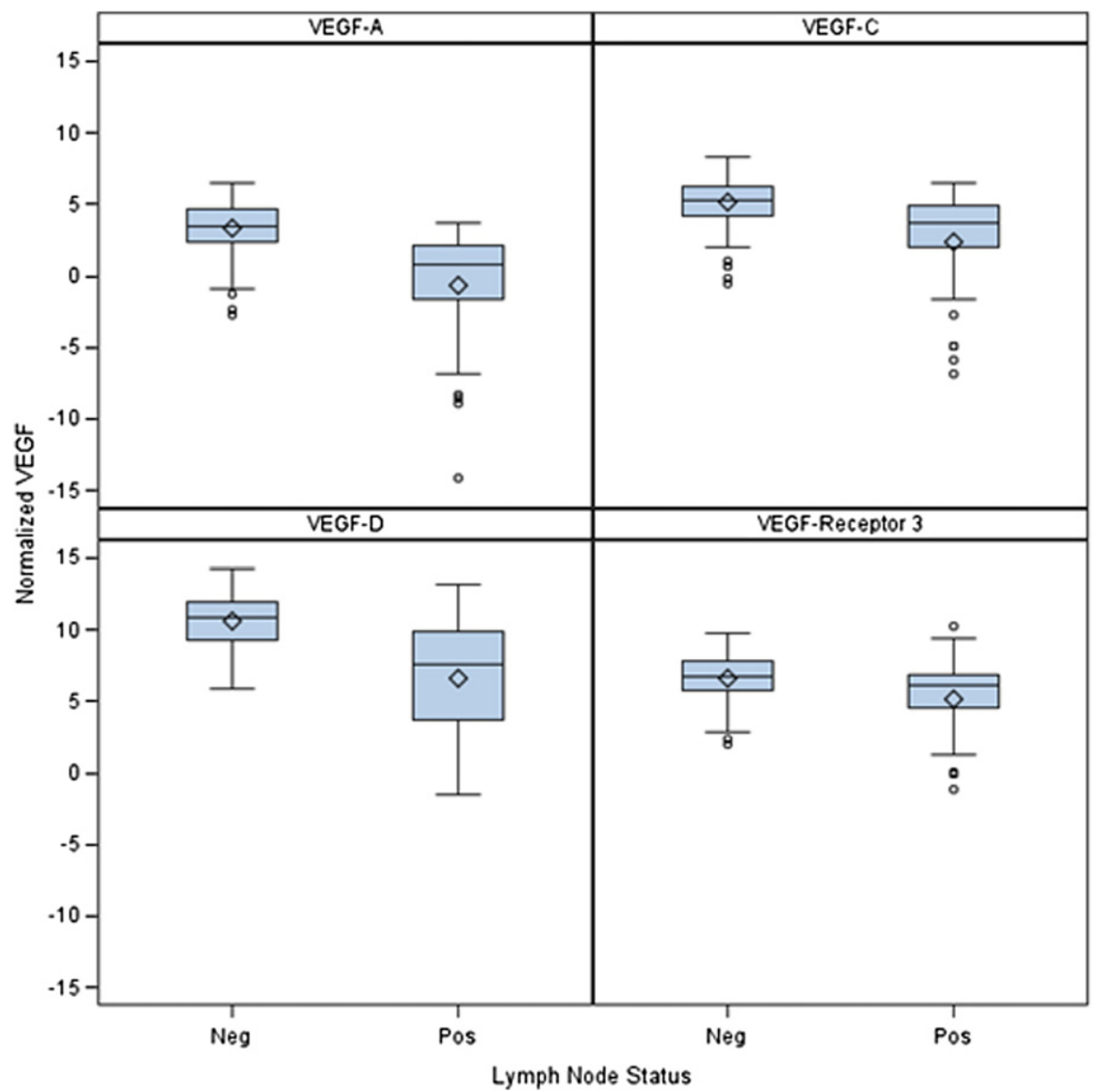

FIGURE 1. Box plots of vascular endothelial growth factor $(V E G F)$ expression (measured as real-time polymerase chain reaction quantification cycle levels) grouped by lymph node micrometastatic status. Lower quantification cycle values reflect higher messenger RNA expression levels.

to investigate if anti-lymphangiogenic treatment can prevent lymphatic and distant metastasis of NSCLC.

Limitations of our study include the fact that not all lymph nodes underwent IHC and RT-PCR analysis. Performing such analysis on every single node would be too laborious and expensive. Also, our short clinical follow-up precludes survival analysis at this time.

\section{CONCLUSIONS}

IHC and RT-PCR analysis for epithelial markers can be used to identify patients with NSCLC with lymph node micrometastatic disease. The presence of micrometastases was associated with higher VEGF-A, VEGF-C, VGEF-D, and VEGF receptor-3 expression in lymph nodes. The influence of these findings on survival will be determined with further follow-up.

\section{References}

1. Siegel R, Naishadham D, Jemal A. Cancer statistics, 2012. CA Cancer J Clin. 2012;62:10-29.

2. Goldstraw P, Crowley J, Chansky K, Giroux DJ, Groome PA, Rami-Porta R, et al. The IASLC lung cancer staging project: proposals for the revision of the TNM stage groupings in the forthcoming (seventh) edition of the TNM classification of malignant tumours. J Thorac Oncol. 2007;2: 706-14.

3. Mountain CF. Revisions in the international system for staging lung cancer. Chest. 1997;111:1710-7.

4. Melfi FM, Lucchi M, Davini F, Viti A, Fontanini G, Boldrini L, et al. Intraoperative sentinel lymph node mapping in stage I non-small cell lung cancer: detection of micrometastases by polymerase chain reaction. Eur J Cardiothorac Surg. 2008;34:181-6.

5. Nwogu C. Sentinel node and positron emission tomography mapping in lung cancer. Semin Thorac Cardiovasc Surg. 2009;21:323-6.

6. Rusch VW, Hawes D, Decker PA, Martin SE, Abati A, Landreneau RJ, et al. Occult metastases in lymph nodes predict survival in resectable non-small-cell lung cancer: report of the ACOSOG Z0040 trial. J Clin Oncol. 2011;29:4313-9.

7. Faries MB, Morton DL. Staging of regional nodes in pulmonary malignancies. Ann Surg Oncol. 2012;19:703-5.

8. Little AG, DeHoyos A, Kirgan DM, Arcomano TR, Murray KD. Intraoperative lymphatic mapping for non-small cell lung cancer: the sentinel node technique. J Thorac Cardiovasc Surg. 1999;117:220-4.

9. Liptay MJ, Masters GA, Winchester DJ, Edelman BL, Garrido BJ, Hirschtritt TR, et al. Intraoperative radioisotope sentinel lymph node mapping in non-small cell lung cancer. Ann Thorac Surg. 2000;70:384-9.

10. Lardinois D, Brack T, Gaspert A, Spahr T, Schneiter D, Steinert HC, et al. Bronchoscopic radioisotope injection for sentinel lymph-node mapping in potentially resectable non-small-cell lung cancer. Eur J Cardiothorac Surg. 2003;23:824-7.

11. Meyer A, Cheng C, Antonescu C, Pezzetta E, Bischof-Delaloye A, Ris HB. Successful migration of three tracers without identification of sentinel nodes during intraoperative lymphatic mapping for non-small cell lung cancer. Interact Cardiovasc Thorac Surg. 2007;6:214-8. 
12. Nwogu C, Fischer G, Tan D, Glinianski M, Lamonica D, Demmy T. Radioguided detection of lymph node metastasis in non-small cell lung cancer. Ann Thorac Surg. 2006;82:1815-20.

13. Jiao X, Krasna MJ. Clinical significance of micrometastasis in lung and esophageal cancer: a new paradigm in thoracic oncology. Ann Thorac Surg. 2002;74: 278-84.

14. Achen MG, Stacker SA. Molecular control of lymphatic metastasis. Ann NY Acad Sci. 2008;1131:225-34

15. Chang C, Wang P, Cheng H, Li L, Yang H, Zhang L. The relationship of VEGF-C, VEGF-D and VEGFR-3 with lymph node metastasis of non-small cell lung cancer. Chin J Clin Oncol. 2009;36:16.

16. Massi D, Gököz Ö. The biological significance of lymphangiogenesis in human tumours. Diagnos Histopathol. 2010;16:295-305.

17. Wissmann C, Detmar M. Pathways targeting tumor lymphangiogenesis. Clin Cancer Res. 2006;12:6865-8.

18. Mountain CF, Dresler CM. Regional lymph node classification for lung cancer staging. Chest. 1997;111:1718-23.

19. Faries MB, Bleicher RJ, Ye X, Essner R, Morton DL. Lymphatic mapping and sentinel lymphadenectomy for primary and metastatic pulmonary malignant neoplasms. Arch Surg. 2004;139:870-6.

20. Gu CD, Osaki T, Oyama T, Inoue M, Kodate M, Dobashi K, et al. Detection of micrometastatic tumor cells in pN0 lymph nodes of patients with completely resected nonsmall cell lung cancer: impact on recurrence and survival. Ann Surg. 2002;235:133-9.

21. Goldstein NS, Mani A, Chmielewski G, Welsh R, Pursel S. Immunohistochemically detected micrometastases in peribronchial and mediastinal lymph nodes from patients with T1, N0, M0 pulmonary adenocarcinomas. Am J Surg Pathol. 2000;24:274-9.

22. Pulte D, Li E, Crawford BK, Newman E, Alexander A, Mustalish DC, et al. Sentinel lymph node mapping and molecular staging in nonsmall cell lung carcinoma. Cancer. 2005; 104:1453-61.

23. Benlloch S, Galbis-Caravajal JM, Alenda C, Peiro FM, Sanchez-Ronco M, Rodriguez-Paniagua JM, et al. Expression of molecular markers in mediastinal nodes from resected stage I non-small-cell lung cancer (NSCLC): prognostic impact and potential role as markers of occult micrometastases. Ann Oncol. 2009; 20:91-7.

24. Hashimoto T, Kobayashi Y, Ishikawa Y, Tsuchiya S, Okumura S, Nakagawa K, et al. Prognostic value of genetically diagnosed lymph node micrometastasis in non-small cell lung carcinoma cases. Cancer Res. 2000;60:6472-8.

25. Stacker SA, Achen MG. From anti-angiogenesis to anti-lymphangiogenesis: emerging trends in cancer therapy. Lymphat Res Biol. 2008;6:165-72.

\section{Discussion}

Dr Raphael Bueno (Boston, Mass). I would like to congratulate you and the rest of the authors from Roswell Park on your successful presentation of this work. I have a few questions. First, you note that the gold standard kept shifting. You show that the gamma probe approach with fludeoxyglucose (FDG) is not sufficiently accurate to identify positive lymph nodes when the gold standard is real-time polymerase chain reaction (RT-PCR), but how good was it when the gamma probe results were compared with the poistron emission tomography-computed tomography (PET-CT) scan or the immunohistology of the lymph nodes?

Dr Chukwumere Nwogu (Buffalo, NY). You're asking how good was the gamma probe in detecting disease?

Dr Bueno. RT-PCR is not something that everybody in the world does. What everybody in the world does is they get a PET scan and they do histology. So when you look at your gamma probe results, you're comparing them to known, defined things; that is, the PET scan and the histology report. How good was it then in terms of sensitivity, specificity, and accuracy?

Dr Nwogu. It was very sensitive in detecting disease. The gamma probe detected activity in all the lymph nodes that were positive using standard histology techniques. The false-positive rate was very high due to inflammation. That's the challenge with using FDG. We definitely need better radioisotopes that will be more specific. Radioisotopes like fluorothymidine are more specific; however, they are less sensitive. We know that a lot of our patients have missed nodal disease, and there are reports indicating a difference in survival based on the presence of RT-PCR positive lymph nodes and negative lymph nodes.

Dr Bueno. My next question is about your patients. About half ended up with positive lymph nodes by RT-PCR, which suggests to me that most of the cases were not TNM Classification System of Malignant Tumors (TNM) stage T1 but might have been stage $\mathrm{T} 2$ or bigger T1s. If that's true, did you stage them up front with mediastinoscopy, or why did you choose to go with surgery?

Dr Nwogu. We staged the disease of all these patients with mediastinoscopy. There were only 2 patients in our overall cohort with positive mediastinal nodes and we did not proceed with surgical resection in those cases. Most of these patients had stage T1 and $\mathrm{T} 2$ lesions. They all were diagnosed with clinical stage I or II disease before surgery.

Dr Bueno. You seem to prefer RT-PCR as your gold standard here, as we just discussed. Do you currently use it clinically, or do you just use it as a research tool? It's not a truly validated, workedout technique, as attractive as it sounds in this study.

Dr Nwogu. We are just using it for research at this point. However, the few patients who were diagnosed with immunohistochemically positive occult disease were referred for a conversation with a medical oncologist about getting adjuvant therapy. If we show that there is a difference in survival between patients who have RT-PCR-diagnosed positive nodes and those who don't, we have to do a clinical trial to justify adjuvant therapy. We haven't gotten there yet.

Dr Bueno. Finally, what this very nicely illustrates is that RT-PCR, which is a little challenging for the pathology labs of most hospitals, is nicely recapitulated in staining with vascular endothelial growth factor (VEGF). Essentially that's what you would expect to do. So are you planning to move in that direction, either to create an isotope for VEGF or have pathologists stain the nodes for one of the VEGFs as a predictor of lymph node status?

Dr Nwogu. We haven't done that yet, but that's a fantastic suggestion and I would definitely like to explore that.

Dr Richard J. Finley (Vancouver, BC, Canada). I would like to ask 1 question about the size of the lymph nodes. Why were you able to pick up so many more lymph nodes with the gamma probe versus the regular PET-CT scan?

Dr Nwogu. I think in some ways it's an unfair comparison between PET-CT and the gamma probe. With PET-CT scans you're looking at a broad view of the thorax and essentially a lot of the lymph nodes that are in the vicinity of the primary tumor are going to be overshadowed by the activity of the primary tumor. Most of these patients had stage I disease. The PET-CT is most likely not going to detect small deposits of cancer in the lymph nodes below a threshold of 5 to $6 \mathrm{~mm}$. However, the gamma probe can be put directly on the lymph node, away from the patient. It can thus detect smaller volume of disease. So by its very nature, the gamma probe will have an advantage.

Dr Gunda Leschber (Berlin, Germany). Do you think the high rate of positive lymph nodes could explain why so many patients in 
the early stages of disease do not do well in the end? The survival rate for patients diagnosed with stage I disease is still not $100 \%$. Do you think that could be an explanation?

Dr Nwogu. Yes. It has been shown in multiple studies, including the recently published Z0040 study results from American College of Surgeons Oncology Group (ACOSOG), that there is a high prevalence of occult metastatic lymph node disease. In that study they showed a prevalence of $22 \%$ for occult lymph node disease, and that was with immunohistochemistry. RT-PCR has been clearly shown to be more sensitive, so we know that there are many patients who have occult disease. How many of them are clinically relevant is a little bit controversial, but research has shown that there's a decrease in survival. So in our case the RT-PCR test was very sensitive in detecting occult disease.

Dr Yolanda Colson (Boston, Mass). You have to be really careful about saying that a gamma probe has increased sensitivity. What it really is, is that it has a high false-positive rate because you have shine-through from the surrounding tumor. Those are two different concepts. It's not really high sensitivity if it spreads everywhere. Clinically we think of this spread as false positives.

How do you know that the VEGF that you're detecting actually pathologically means anything? Is it truly metastasis? You're not seeing it any other way that you have to detect it. Does it mean anything or is it just a marker of inflammation in that node or new lymphatic pathways, but not necessarily metastasis?

Dr Nwogu. That's a very good question. Given the fact that we don't have a really good gold standard to assess RT-PCR, what we have to rely on is the recurrence rate. Our current median followup is $\mathbf{1 2 . 6}$ months. Right now, we have too few events to really see a statistical difference in recurrence rate between the patients with RT-PCR negative nodes and the patients with RT-PCR positive nodes, but when we have longer follow-up and more events, we can determine if there is a difference in recurrence between the 2 groups of patients.

The detected gamma probe radioactivity was not from shinethrough from the primary tumor. The measurements were taken after lymph nodes were dissected away from the lung. 